\title{
EPIDEMIOLOGY OF CHILDHOOD BLINDNESS
}

\author{
ALLEN FOSTER and CLARE GILBERT \\ London
}

\begin{abstract}
SUMMARY
In this paper an attempt is made to define, quantify and determine the causes of childhood blindness in different parts of the world, with particular emphasis on blinding diseases which are detectable during the neonatal period.
\end{abstract}

The patterns of childhood blindness vary depending on the accessibility of affordable health care services as well as socio-cultural factors. A major cause of childhood blindness in one country can be insignificant in another, and even over a decade the causes of childhood blindness can change quite dramatically in the same country. Clear definitions are necessary in order to develop reasonable estimates of the size of the problem of childhood blindness, and of the major disease processes in different parts of the world. Once this information is available control strategies can be developed to reduce the incidence of childhood blindness through both preventive and therapeutic measures.

\section{TERMINOLOGY}

Childhood is defined by UNICEF as 0-15 years. Blindness is defined by the World Health Organisation as a corrected visual acuity in the better eye of less than $3 / 60$, or a central visual field of less than $10^{\circ}$ (Table I). ${ }^{1}$ The assessment of vision in the newborn or even the young infant can be extremely difficult. By early childhood however (age 2-3 years) it is usually possible to determine the level of visual capacity with a careful examination of the eye and a functional assessment of the child's ability to see.

\section{MAGNITUDE}

There are very little data available on the prevalence of childhood blindness from population based studies. Prevalence and incidence data from blind registers usually under-estimate the true figure because of under-reporting. ${ }^{2}$ Table II summarises the available data from different parts of the world. ${ }^{3}$ Using these data a World Health Organisation meeting on Childhood Blindness in 1990 estimated that there were approximately 1.5 million blind

Correspondence to: Allen Foster, FRCS, FCOphth, International Centre for Eye Health, 27-29 Cayton Street, London EC1V 9EJ. children in the world of which $90 \%$ live in developing countries. ${ }^{4}$ It was also estimated that approximately 500,000 children go blind each year in the world of which $60-80 \%$ die within the subsequent $1-2$ years from the diseases which contributed to their blindness or from neglect consequent upon being blind. ${ }^{4}$

The prevalence of blindness in children is closely related to the availability of health care for children (nutrition, immunisation etc) and therefore also to child survival and under five mortality rates (U5MR). Countries with high U5MR (in excess of 170/1,000) are likely to have a prevalence of childhood blindness in excess of one per thousand, while those countries with low U5MR (below $30 / 1,000$ ) probably have a prevalence of between $0.2-0.5$ / 1,000 children. In Table III an attempt is made to correlate U5MR in various parts of the world with childhood blindness.

The only data on incidence of childhood blindness come from blind registrations in developed countries. The data for England are given in Figure 1.5 Robinson reviewed the prevalence of congenital blindness in British Columbia from 1945-1984 showing a fairly constant figure for congenital blindness of $4 / 100,000$ births from $1955-80 .^{6}$

In summary therefore, little information is available on the magnitude of childhood blindness, although current estimates would suggest that the majority of childhood blindness occurs in Asia and Africa; that many blind children in developing countries die in childhood; and that with an increase in the childhood population (estimated at

Table I. Categories of Visual Impairment ${ }^{1}$

\begin{tabular}{|c|c|c|c|}
\hline \multirow{2}{*}{\multicolumn{2}{|c|}{$\begin{array}{l}\text { Category of } \\
\text { Visual impairment }\end{array}$}} & \multicolumn{2}{|c|}{$\begin{array}{l}\text { Visual acuity with best possible } \\
\text { correction }\end{array}$} \\
\hline & & $\begin{array}{l}\text { Maximum } \\
\text { less than }\end{array}$ & $\begin{array}{l}\text { Minimum equal to } \\
\text { or better than }\end{array}$ \\
\hline 1 & Visual Impairment & $6 / 18$ & $6 / 60$ \\
\hline 2 & Severe Visual Impairment & $6 / 60$ & $3 / 60$ \\
\hline 3 & Blind & $3 / 60$ & $1 / 60$ \\
\hline 4 & Blind & $1 / 60$ & Light perception \\
\hline 5 & Blind & \multicolumn{2}{|c|}{ Light perception No light perception } \\
\hline
\end{tabular}


Table II. Prevalence of Childhood Blindness

\begin{tabular}{lllc}
\hline Country (Ref) & Year & \multicolumn{2}{c}{ Prevalence/1000 } \\
\hline England (5) & 1981 & 0.10 & $(0-4$ years $)$ \\
& & 0.22 & $(5-9$ years $)$ \\
Bangladesh (18) & 1983 & $0.23(10-14$ years) \\
& & 0.64 & $(0-5$ years, rural $)$ \\
Nepal (19) & 1980 & 1.09 & $(0-5$ years, urban $)$ \\
Malawi (20) & 1983 & 0.63 & $(0-14$ years) \\
The Gambia (21) & 1986 & 0.1 & $(0-5$ years) \\
\hline
\end{tabular}

2,025 million by the year 2,000 ) the number of blind children is likely to increase from the present estimate of 1.5 million.

\section{AETIOLOGY}

Childhood blindness can be usefully classified from an aetiological viewpoint into:-

-factors which act at the time of conception, e.g. genetic and chromosomal abnormalities

-factors operating during the intra-uterine period, e.g. infections (rubella, toxoplasmosis), toxins (alcohol, quinine)

-factors operating at the time of birth or during the postnatal period, e.g. cerebral hypoxia, retinopathy of prematrity and ophthalmia neonatorum

- factors operating in childhood, e.g. vitamin A deficiency, trauma.

An anatomical classification of blindness in children is also of value as it may be difficult to determine whether, for example, optic atrophy is hereditary in origin, or due to toxins acting during pregnancy, or due to hypoxia or trauma consequent upon birth, or secondary to meningitis in early childhood. This is particularly the situation in developing countries where details of past medical history may not be available. An anatomical classification can be used to describe differences in the patterns of childhood blindness between different countries, and in the same country over time. For example, corneal blindness is particularly common in parts of Africa accounting for $40-70 \%$ of childhood blindness, ${ }^{7.8}$ but is extremely uncommon in Europe, where retinal diseases, particularly dystrophies and retinopathy of prematurity, are responsible for approximately a quarter of blindness in children. ${ }^{9,13}$ In Table IV a correlation is given between the aetiological and anatomical classifications in respect to major causes of childhood blindness from a global perspective.

Genetic factors are the prevailing cause of childhood blindness in societies which have developed good health services for children, e.g. Europe and North America, and in those communities in which, for either cultural or geographical reasons, consanguinity is common, e.g. ethnic minorities, small island communities etc. ${ }^{12.6 .9 .10 .15}$

Relatively little is known about the role of infections or toxins in causing developmental damage to the eye in utero. Rubella remains an endemic disease in most parts of the world, but fortunately the majority of females contract the disease in childhood so acquiring natural immunity. In many societies, however, a small percentage of child bearing women will be susceptible to infection and therefore, following intermittent but regular epidemics of rubella, a cluster of often multiply handicapped children are born. In many parts of the world the multiply handicapped child does not survive to school age. Rubella begins to become a significant cause of childhood blindness in those countries where blindness from malnutrition and measles have been erradicated but where rubella immunisation either of school age girls or as part of a universal child immunisation programme has not yet been introduced. Isolated communities (e.g. small islands), because of the irregularity of rubella epidemics, tend to produce populations with more susceptible females of child bearing age and hence occasional epidemics of children with congenitally acquired rubella."

The fetal alcohol syndrome is becoming an increasingly well recognised cause of congenital ocular abnormalities particularly of optic nerve hypoplasia, ${ }^{12}$ and it is quite likely that other products, medicines or environmental substances will be found to have a harmful effect on the developing eye and particularly the optic nerve. Optic atrophy accounts for more than a quarter of childhood blindness in England ${ }^{13}$ and a recent study from Eire documented optic nerve disease being responsible for over $40 \%$ of childhood blindness. ${ }^{9}$

The premature baby is particularly at high risk of visual loss from perinatal factors. Cerebral hypoxia may result in damage to the visual cortex or pathways and is often associated with other central nervous system abnormalities. Retinopathy of prematurity (ROP) can occur in babies with a birthweight under $1.5 \mathrm{~kg}$. In countries with excellent neonatal care services the increased survival of very

Table III. Magnitude of Childhood Blindness in Different Countries by Under 5 Year Mortality Rate (U5MR) (1988)

\begin{tabular}{|c|c|c|c|c|}
\hline U5MR/1000 & $\begin{array}{c}\text { Under } 16 \text { yrs } \\
\text { Population } \\
\text { (millions) }\end{array}$ & $\begin{array}{l}\text { Example } \\
\text { Countries }\end{array}$ & $\begin{array}{c}\text { Estimated } \\
\text { Prevalence/ } \\
1000\end{array}$ & $\begin{array}{c}\text { Number of } \\
\text { Blind } \\
\text { Children }\end{array}$ \\
\hline Very High $(171+)$ & 233 & $\begin{array}{c}\text { Nigeria } \\
\text { Bangladesh }\end{array}$ & 1.5 & 350,000 \\
\hline High $(95-170)$ & 613 & $\begin{array}{l}\text { India } \\
\text { Kenya }\end{array}$ & 0.9 & 613,000 \\
\hline Middle (31-94) & 706 & $\begin{array}{l}\text { China } \\
\text { Brazil }\end{array}$ & 0.6 & 424,000 \\
\hline Low (30) and under) & 212 & $\begin{array}{c}\text { USA } \\
\text { France }\end{array}$ & 0.3 & 63,000 \\
\hline & 1,764 & & & $1,450,000$ \\
\hline
\end{tabular}




\section{ENGLAND 1976 - 1984, INCIDENCE OF NEW BLIND REGISTRATIONS AGE 0-15YrS}

\section{ENGLAND 1976-1984, INCIDENCE OF NEW BLIND REGISTRATIONS AGE 0-15yrs}

\begin{tabular}{lr} 
YEAB & Ne \\
$1976 / 77$ & 223 \\
$1977 / 78$ & 209 \\
$1978 / 79$ & 216 \\
$1979 / 80$ & 213 \\
$1980 / 81$ & 191 \\
$1981 / 82$ & 184 \\
$1982 / 83$ & 213 \\
$1983 / 84$ & 217 \\
$1984 / 85$ & 285 \\
\hline \multicolumn{2}{l}{ Mean 217 } \\
95\% C.L. 160-274 \\
S.D. 28.6 \\
\hline
\end{tabular}

Fig 1

low birth weight infants is resulting in a re-emergence of ROP as an important cause of childhood blindness. In other countries, e.g. parts of Latin America and Asia, the use of high dose, often unmonitored oxygen in neonates is only now being recognised as a significant and preventable cause of visual loss. While in the poor areas of the world ophthalmia neonatorum due to Neisseria gonococcus occurring in the first week after birth, may remain untreated because of inadequate eye care services resulting in corneal ulceration and blindness in the neonatal period. ${ }^{14}$

The most important cause of childhood blindness on a worldwide basis is corneal ulceration due to vitamin A deficiency. This occurs most commonly in children aged between one and four years and often follows measles infection or severe gastroenteritis. The use of harmful traditional medicines in areas without eye or health care is also an important cause of childhood blindness. ${ }^{8.14}$

\section{GEOGRAPHIC DISTRIBUTION}

The causes and time of onset of childhood blindness vary from one part of the world to another. Table $\mathrm{V}$ summarises the anatomical cause of blindness in children in blind schools in different regions of the world from examin-

\section{ENGLAND 1976-1984, INCIDENCE OF NEW BLIND REGISTRATIONS AGE 0-15yrs}

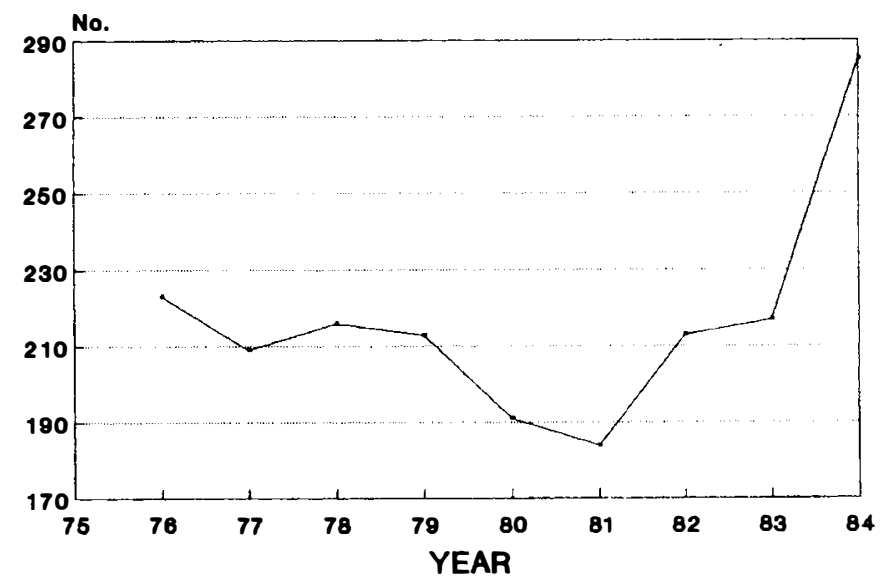

ations conducted since 1975 . These show the importance of corneal diseases acquired during childhood in East Africa (70\%), West Africa (40\%) and South Asia (30\%). Cataract is usually found to be responsible for between $5-20 \%$ of blindness in children. Unoperated mature cataracts in children are seen in around $10 \%$ of children in blind schools in developing countries.

Retinal causes of visual loss which may present during infancy include retinal dystrophies, and retinopathy of prematurity. These account for $20-30 \%$ of cases in South Asia, Latin America and Europe. Glaucoma at birth or in childhood is relatively uncommon although it does account for $5-10 \%$ of blindness in children from West Africa, South Asia and Latin America. Optic nerve disease as already mentioned is an increasingly important cause in industrialised countries.

Studies in various countries have noted the changing pattern in childhood blindness over time. In Saudi Arabia acquired childhood diseases accounted for $75 \%$ of childhood blindness prior to 1962, while genetically determined diseases accounted for $84 \%$ of childhood blindness after $1962 .{ }^{15}$ Similarly in Kenya corneal scarring has been observed to be less of a problem now than ten years ago, ${ }^{16}$ and in Chile there is evidence that ROP is becoming an

Table IV. Relationship between Aeitological and Anatomical Causes of Childhood Blindness for Major Blinding Diseases in Children

\begin{tabular}{|c|c|c|c|c|}
\hline & Cornea & Lens & Retina & Optic nerve \\
\hline Genetic Factors & Rare & Familial cataract & Inherited dystrophies & Inherited optic atrophy \\
\hline In-utero Factors & Rare & Rubella & Toxoplasmosis & Alcohol and other toxins \\
\hline Childhood Factors & $\begin{array}{l}\text { Vit A deficiency } \\
\text { Measles } \\
\text { Harmful medicine }\end{array}$ & Rare & Retinal detachment & Meningitis, neoplasia \\
\hline
\end{tabular}


Table V. Childhood Blindness in Different Areas of the World by \% Anatomical Cause: 1975-1991

\begin{tabular}{|c|c|c|c|c|c|c|c|}
\hline $\begin{array}{l}\text { Area of world } \\
\text { (no. of blind children exam) }\end{array}$ & Cornea & Lens & Uvea & Retina & Glauc. & $\begin{array}{l}\text { Optic } \\
\text { Atrophy }\end{array}$ & Others \\
\hline East Africa ${ }^{1}(n=1845)$ & 72 & 6 & 2 & 3 & 1 & 6 & 10 \\
\hline West Africa $(n=567)$ & 39 & 15 & 6 & 11 & 10 & 7 & 12 \\
\hline South Asia ${ }^{1}(n=424)$ & 33 & 7 & 1 & 20 & 5 & 5 & 29 \\
\hline Latin America' $(n=991)$ & 8 & 20 & 1 & 26 & 10 & 10 & 25 \\
\hline Europe $/$ N. America ${ }^{2}(n=1806)$ & 1 & 8 & 1 & 30 & 2 & 23 & 35 \\
\hline
\end{tabular}

'Data from surveys of the causes of blindness in children attending blind schools.

${ }^{2}$ Data from registrations of blind children and examination of blind children in institutions.

increasing problem. ${ }^{17}$ It is therefore important that data be obtained either from registrations or from regular examination of blind school children to document the changing patterns of childhood blindness so that appropriate control measures can be implemented.

\section{CONTROL MEASURES}

It is not possible to go into any depth concerning all the possible control measures, but certain general comments can be made. First, at least $50 \%$ and probably $75 \%$ of childhood blindness in the world is potentially preventable or curable with today's knowledge. Secondly, each country needs to determine the important causes of childhood blindness and develop appropriate programmes for the prevention or cure of these causes. Thirdly, in order to develop control measures against childhood visual loss, an integrated approach involving community paediatricians, experts in special education, ophthalmologists and health planners is required, together with appropriate specialised personnel as indicated, e.g. geneticists, nutritionists, neonatologists etc.

\section{CONCLUSION}

Of the estimated 1.5 million blind children in the world 1.3 million live in Asia and Africa and probably $75 \%$ of causes are preventable or curable. More information is needed on the magnitude and severity of visual loss in children in different parts of the world, and on the changing patterns of childhood blindness over time in individual countries. This information, when available for each country, should be used to develop a co-ordinated and integrated control programme against the important causes of avoidable blindness in children in each individual country.

\section{REFERENCES}

1. Strategies for the Prevention of Blindness in National Programmes. Geneva: World Health Organisation, 1984.

2. Jay B: Causes of blindness in school children. $\mathrm{Br}$ Med J 1987, 291: 1183-4.

3. Foster A and Johnson GJJ: Magnitude and Causes of Blind- ness in the Developing World. Internat Ophthalmol 1990, 14: $135-40$.

4. Report of the WHO Meeting on the Prevention of Childhood Blindness. Geneva: WHO/PBL, 1990. 90.19 (Unpublished document)

5. Initial Demographic Study 1985. A review of the available data on the visually disabled population. London: Royal National Institute for the Blind, 1985.

6. Robinson GC, Jan JE, Kinnis C: Congenital Ocular Blindness in Children 1945-84. Am J Dis Child 1987, 141: 1321-4.

7. Foster A: Childhood Blindness. Eye 1988, 2 Supplement: S27-S36.

8. Chirambo MC: Causes of blindness among students in blind school institutions in a developing country. BrJ Ophthalmol 1976, 60: 655-68.

9. Goggin $\mathbf{M}$ and O'Keefe $\mathbf{M}$ : Childhood blindness in the Republic of Ireland: a national survey. $\mathrm{Br} J$ Ophthalmol 1991, 75: 425-9.

10. Merin S, Lapithis AG, Horovitz D, et al.: Childhood blindness in Cyprus. Am J Ophthalmol 1972, 74: 538-42.

11. Moriarty B: Childhood blindness in Jamaica. Br J Ophthalmol 1988, 72: 65-7.

12. Chan T, Bowels R, O'Keefe M, Lanigan B: Ocular manifestations in fetal alcohol syndrome. Br J Ophthalmol 1991, 75: $524-6$.

13. Statistical Bulletin. DHSS. 5/86. London: Department of Health.

14. Foster A and Sommer A: Corneal ulceration, measles and childhood blindness in Tanzania. Br J Ophthalmol 1987, 71: $331-42$.

15. Tabbara KF and Badr IA: Changing Patterns of Childhood Blindness in Saudi Arabia. Br J Ophthalmol 1985, 69: 312-15.

16. Wood M: Personal Communication.

17. Gilbert C, Canovas R, Foster A: Causes of childhood blindness in Chile. (In press).

18. Cohen N, Rahman H, Sprague J, Jahl M, Leambujis E, Mitra M. Prevalence and determinants of nutritional blindness in Bangladeshi children. World Health Statistics Quarterly 1985, 38: 317-29.

19. Brilliant GE, et al.: The epidemiology of blindness in Nepal. The Seva Foundation USA, 1988.

20. World Health Organisation: Available data on blindness (Update 1987). Geneva: WHO. WHO/PBL/87.14.

21. Faal H, Minassian D, Sowa S, Foster A: National survey of blindness and low vision in The Gambia: Results. Br J Ophthalmol 1989, 73: 82-7. 